\title{
Digital Scholarship in Translation Studies: a Plea for Openness
}

Peter Sandrini

University of Innsbruck, Austria

Free and open source software defines openness with regard to the free availability of the source code and the binary program. Beyond free availability and gratuitousness, however, there is a more profound rationale behind the concept of openness, touching the question of social equality when referring to knowledge and education, as well as to the ownership of knowledge in general. The academic world, and researchers in particular, are at the core of this challenge which has intensified significantly with globalization tendencies and the digital revolution. Theoretically, principles and practice of academic work remain the same: researchers and scholars still strive for valid and trustworthy methods of inquiry. The environment in which studies are carried out, documented and published, though, has undergone deep changes. It provides new possibilities, linking the practice of scholarship with the possibilities of digital technology and new media. Digital scholarship has many dimensions and may be defined as "the use of digital evidence and method, digital authoring, digital publishing, digital curation and preservation, and digital use and reuse of scholarship" (Smith Rumsey 2013: 158).

The following paper concentrates on the concept of openness in the use of digital technology and digital media in academic research, and Translation Studies (TS) in particular, leaving aside the exploration of openness within two other important areas of digital scholarship: the use of digital technology in education and training, as well as the study and analysis of the digital medium itself.

To this end, we need to take a look at publication methods, access options to publications, as well as academic evaluation methods in TS, a research field where we have to deal with the peculiarity of different publication languages and a variety of competing research methods and theories.

It is evident that digital scholarship or the "scientist 2.0" as called by Agnetta (in this volume) cannot elude the problems and common trends of the new digital world, and openness seems to be one of them. Discussions about open source code, open knowledge, open content, open data, open education, etc. have lead the way to the question of openness in research, openness in publishing research results, or open access. This paper wraps up the situation in TS and makes a plea for openness since more openness could foster the discipline as a whole and move it towards a more unified and collaborative field of study. 


\section{Open Access Publishing}

The statements in this paper are based on the following assumptions regarding research publications, even if they are taken for granted by a majority of researchers and aptly called 'truisms' by Blommaert (2014: 6):

- the main purpose of publishing is finding a readership;

- research doesn't make sense without publishing results;

- the less barriers between potential readers and research results the better reception and response from readers, colleagues and fellow researchers.

At the beginning of modern scholarship Aristotle stated in his Metaphysics 'All humankind by nature desires to know' and Wilinsky (2006) deduces: "As this desire is rightly identified, I believe, as part of our nature, it stands as a human right to know" (Willinsky 2006: 27). The right to know on the side of the public is complemented by the desire to communicate on the side of researchers, and publishing is the medium of choice for academia.

The field of publishing in TS is very heterogeneous and distributed over different countries and languages, a fact called by Gile (2015: 240) "the geographic, thematic and methodological fragmentation of TS". Different countries have developed diverse theoretical approaches, and very often language barriers prevent adoption and discussion of foreign theories. Nevertheless, the specific object of study as such represents "more of an interlingual, cross-cultural, interdisciplinary, and supranational subject of international interest" (Xiangdong 2015: 184). Referring to the first outline of the discipline published by James S. Holmes in 1972, Xiangdong then goes on: "The main research areas in Holmes's' map of TS, for example, theoretical studies, descriptive studies, translator training, translation aids, and translation criticism, are all topics of global interest" (Xiangdong 2015: 184). A common scientific basis as well as knowledge of seminal publications and the most important theoretical approaches, independently of the language in which they were originally written, all this constitutes a precondition for a sound subject field, and a prerequisite for an evolving discipline.

Furthermore, TS is not always recognized as an autonomous discipline, but rather subsumed under linguistics, comparative literature, philology or communication studies in general (Rovira-Esteva and Orero 2012, Gentzler 2014, Xiangdong 2015). These factors make TS a challenging discipline when it comes to research and evaluation: access to theoretical literature and publications is essential for the first, consideration of the peculiarities and idiosyncrasies of the subject field fundamentally important for the second. 
What may keep researchers from accessing relevant literature is financial barriers, restrictions in place and time, as for example location and opening times in public libraries, availability of publications, etc. A first step in overcoming those barriers was the advent of the Web with new possibilities for independent publication of all kinds of texts, enabling at the same time Online Public Access Catalogs (OPACS) which made meta information on publications freely available. A second and more important step was the removal of legal and financial barriers by introducing new license models, such as, for example, the 'Copyleft' model of free software, or the 'Creative Commons' licenses, as well as open access publication models.

The definitions of Open Access (OA) are not always clear-cut or consistent: broad descriptions define OA as being found freely available online, others describe it as the "removal of barriers (including price barriers from accessing scholarly work" (Eysenbach 2006: 1). The founding papers and declarations of OA provide a more detailed description:

"free availability on the public Internet, permitting any users to read, download, copy, distribute, print, search, or link to the full texts of these articles, crawl them for indexing, pass them as data to software, or use them for any other lawful purpose, without financial, legal, or technical barriers" (Budapest Open Access Initiative 2002).

For a work to be OA, the copyright holder must consent in advance to let users "copy, use, distribute, transmit and display the work publicly and to make and distribute derivative works, in any digital medium for any responsible purpose, subject to proper attribution of authorship" (Berlin Declaration 2003).

This is in open contrast to the copyright policies of commercial publishers who make researchers sign contracts which force them to hand over all rights to the publisher, in many cases even the right of re-use of published material, for example on a researcher's personal website. Such copyright agreements commonly impose severe restrictions on use while OA is the immediate, online, free availability of research output. The absence of legal barriers implies the existence of appropriate legal licenses. A suitable proposal has been developed by the Creative Commons (CC) framework shortly before the OA declarations, with the intention of creating a license model that enables people to "share your knowledge and creativity with the world" (creativecommons.org) in order to "maximize digital creativity, sharing, and innovation" (creativecommons.org). It offers six licenses based on a combination of the following rights modules: by (attribution), nc (non commercial), nd (no derivatives), sa (share alike), plus the public domain license CCO (no copyright). As good practice in research already imposes, all six CC licenses require attribution of authorship; the nd restriction does not lend itself to research since 
research heavily builds upon previous publications and it would be bad research if everybody should start anew from scratch.

It is precisely the fear of copyright violation, of lack of attribution, or the fear of unhindered stealing of ideas ('scooping') which keeps many scholars from embracing OA publication models although this is explicitly catered for by the different $\mathrm{CC}$ licenses. Yet, this reservation is expressed very often as an argument against OA, brought forward mainly by senior researchers who are not very familiar with new media. Being freely available, OA publications can be read and re-used by everyone, sometimes even copied illegally, but at the same time, any infringement on copyright can be easily identified through plagiarism checkers, even more so with OA online publications than with closed or restricted publications which are not always accessible to this kind of software checkers.

The main advantage of OA is the removal of obstacles between author and readers, opening up access for those who need it: scholars from small institutions and developing countries, patient advocates, patients themselves, and lay scholars. Basically, research and scholarly communication should be considered as a public good and publishing of research should be treated as such. Most research in translation is conducted by state-employed university staff paid for by the public. Thus, a certain moral obligation exists to make research outcome accessible to the public. Commercial publishers normally require authors to pay a publication fee which researchers usually take from institutional or public research funds, equally paid for by taxpayers, and then publishers charge the public, taxpayers again, money for the same publications in book form: thus, the public pays three times basically for the same research results.

John Willinsky, one of the world's leading advocates of OA, sees the free exchange of information as a matter of social justice, and estimates that already around 20-25 per cent of all peer-reviewed material currently published is now OA (Willinsky 2006).

Opening up readership means more readers who will read, process and absorb published ideas. An empirical study in physiology showed "full text downloads were $89 \%$ higher, PDF downloads $42 \%$ higher, and unique visitors $23 \%$ higher for open access articles than for subscription access articles" (Davis et al 2008), a result subsequently corroborated by another study involving 36 participating journals in the sciences, social sciences, and humanities, reporting that OA articles "received significantly more downloads and reached a broader audience within the first year, yet were cited no more frequently, nor earlier, than subscription-access control articles within 3 years" (Davis 2011: 2129), a finding confirmed elsewhere as well: "OA articles are 
cited earlier and are, on average, cited more often than non-OA articles" (Eysenbach 2006: 696).

A larger readership results in increased uptake of research results and ideas, leading to a higher citation rate, indicating "that authors are finding them more easily, reading them more often, and therefore citing them disproportionately in their own work" (Antelman 2004: 377). The observation that $\mathrm{OA}$ articles receive more citations than subscription-based articles is known as the OA citation advantage (OACA): "it is clear that the advantage exists and occurs regularly across a range of subject areas" (Norris et al 2008: 1970). Eysenbach (2006) proposes a study with similar results in favor of OA publications for the subject field of biology, stating that "OA articles compared to non-OA articles remained twice as likely to be cited [...] in the first 4-10 mo after publication [...], with the odds ratio increasing to $2.9[\ldots]$ 10-16 mo after publication" (Eysenbach 2006: 1). Another study (Antelman 2004) investigates

"articles in four disciplines at varying stages of adoption of open access - philosophy, political science, electrical and electronic engineering and mathematics to see whether they have a greater impact as measured by citations in the ISI Web of Science database when their authors make them freely available on the Internet. The finding is that, across all four disciplines, freely available articles do have a greater research impact" (Antelman 2004: abstract).

The website SPARC Europe lists 46 studies that found a citation advantage, 17 studies that found no citation advantage, and 7 studies "that were inconclusive, found non-significant data or measured other things than citation advantage for articles" (http://sparceurope.org/oaca/).

Once OA publications are beginning to appear readers "lower the threshold of effort they are willing to expend to retrieve documents that present any barriers to access. This indicates both a "push" away from print and a "pull" toward open access, which may strengthen the association between open access and research impact" (Antelman 2004: 377).

Notwithstanding all this, OA as it is managed today still presents serious shortcomings: "even if publishing in an open-access journal were generally associated with a $10 \%$ boost in citations, it is not clear that authors in economics and business would be willing to pay several thousand dollars for this benefit, at least in lieu of subsidies" (McCabe and Snyder: 2013: 31) referring to the OA models often adopted by commercial publishers. In many cases, national funding bodies require research results to be published in an OA environment, and due to indirect assessment - a model very often used for the evaluation of personal careers - with the ranking of journals and publishers dictating where to publish (mostly commercial publishers and sub- 
scription-based journals), and, thus, forcing upon researchers a rather expensive publication option, "authors simply have to go for the expensive Open Access strategy (aptly called 'Gold Open Access')" (Blommaert 2014: 3 ), thereby supporting a barefaced "robber economy" as a "no- risk enterprise in its most extreme shape" (Blommaert 2014: 4). If a researcher does not comply with this approach, insisting on his freedom of choosing other publication options, this often results in a lack of prestige when his/her articles or books are published in journals or with publishers that are not listed in the rankings.

Along with top ranking goes visibility of articles in a discipline, and, conversely, research results published in journals or with publishers which are not listed in the rankings may not be immediately appreciated by colleagues and fellow researchers. However, there are quite a few OA repositories and search platforms available today where OA publications can be searched for on the basis of their metadata, and downloaded:

- the OAlster Database (oaister.worldcat.org) with records of digital resources from open-archive collections worldwide;

- the Directory of Open Access Journals DOAJ (doaj.org) with more than 600 searchable journals;

- The Directory of Open Access Repositories - OpenDOAR (opendoar.org), a directory of academic open access repositories;

- BioMed Central (biomedcentral.com), Open Access journals covering all areas of Biology and Medicine;

- Public Library of Science (PloS) (plos.org), a nonprofit scientific and medical publishing venture using the Creative Commons Attribution License;

- PLEIADI Portal for the Italian Electronic Literature in Open and Institutional Archives (openarchives.it/pleiadi/);

- OAPEN Open Access Publishing in European Networks (oapen.org), an online library and publication platform;

- SHERPA/RoMEO, a database about publisher copyright policies \& selfarchiving options.

Openness in publishing and the institution of freely accessible publication archives even seem to promote the international ranking of universities as empirical studies show (Olsbo 2013); I will come back to the problems of evaluation and assessment of research in more detail below.

From the viewpoint of authors, scholars or researchers the positive aspects of OA clearly prevail: OA brings greater impact, dissemination of research results is faster, it enables better management and assessment of 
research, and provides new opportunities for linking and online text-mining, as well as a degree of productive collaboration otherwise not possible.

Coming back to TS, a look at the relevant journals and their publishing policies seems to suggest that OA journals are on the rise. There are several listings of relevant journals in TS, amongst others:

- RETI (RETI n.d.): Revistes dels Estudis de Traducció et Interpretació of the Autonomus University of Barcelona lists a total of 421 titles with many journals from neighboring disciplines such as linguistics and literature, out of which 161 (38 \%) are found to be OA.

- Another list of 55 journals publishing TS research, published on Academia.edu by James Hadley, reports 20 OA titles or $36 \%$ electronically available as PDF files free of charge and without any subscription fee.

- The European Society for TS (EST) has a draft listing of 125 journals, 57 of which are found to be OA (46\%), 5 partly (4\%), 3 limited (2\%), 2 first issue only (2\%) and 50 subscription-based (40\%), 8 not declared $(6 \%)$.

- The recent list of active Journals in TS by Franco Aixelá/Rovira-Esteva (2015) in the special issue of Perspectives sees a majority of OA titles, 58 or $52 \%$ against 54 or $48 \%$ with toll access, out of a total of 112 journals.

Not taking into account the different inclusion criteria depending on categorization and discipline boundaries, the average ratio of OA journals in these lists is a hefty $43 \%$, a high percentage, also confirmed by a study for the European Commission which found that "18\% of biology papers published in 2008-11 were open access from the start, and said that $57 \%$ could be read for free in some form, somewhere on the Internet, by April 2013" (Noorden 2014: 128). In addition, the OA options for the publication of monographs and edited volumes, in TS more important than journals (Franco Aixelá and Rovira-Esteva 2015: 270; AQU Workshop 2010: 7), with big publishing houses are increasing, even if many of them are offering OA only on a very expensive basis. Small publishing enterprises by local universities seem to be the best option at this time as their OA price policies are much more accessible to constantly under-funded researchers.

Today, OA has ceased to be a rather strange, or a niche publishing option, and already begins to rival traditional publishing methods. Seen from the viewpoint of researchers and put in more ideological terms, it boils down to the question: Do I want my ideas and research results to be sold by commercial companies with the respective financial burden on potential 
readers, or do I want them to be open and accessible to as many readers as possible?

\section{Social Media for Researchers}

New media present researchers with new and totally independent publication options, each of which with specific advantages and disadvantages, as well as a varying degree of openness. Scholars may have personal websites where articles, studies and monographs can be made accessible after their publication in journals or books if copyright contracts allow them to do so - a method called self-archiving - or even original work published for the first time. The problem with this form of independent publishing is that it will be difficult or nearly impossible for authors to reach a clearly defined target audience, usually fellow researchers from the same discipline or scholars from wider neighboring subject fields. Though self-archiving facilitates free access to publications, it does nothing to support collaboration and communication between scholars.

Social media platforms for scholars try to remedy this by devising convenient collaborative websites which allow scholars to share their works, reach the intended audience and get feedback at the same time, they enable social interaction. While such tools are already very popular for general purposes on the Internet (Facebook, LinkedIn, Twitter), for photo sharing (Flickr, Instagram), for Video sharing (YouTube), etc. they are gaining popularity in academia as well, either as a substitute for self-archiving, as a secondary publication method, or simply as a place to discuss research results and ideas: "such sharing tools are, in effect, perhaps the most 'ecological' tool available at present" (Blommaert 2014: 11). Online community resources for scholars and scientists from many disciplines give their "members a place to create profile pages, share papers, track views and downloads, and discuss research" (Noorden 2014: 126). The most prominent examples (Noorden 2014) are briefly discussed here from the perspective of their openness.

\subsection{Google Scholar}

Google Scholar is a specialized tool to search for scholarly literature. It allows researchers to explore related works, citations, authors, publications, and proposes links to complete documents. Citations of individual publications can be checked to see how often a paper has been cited, who cited the publication in which document and whether the document is freely available.

In addition, Google scholar offers the possibility to create a kind of homepage for each researcher, called the public author profile, that incorporates 
his/her publications and a citation analysis. The number of citations is indicated for each individual publication, as well as for the researcher in total, and compiled into the h-index (see below).

For researchers, Google Scholar represents a very powerful tool that reveals relevant links between publications and authors, and offers one of the most comprehensive citation analyses. Critics (Fell 2010) point out that the algorithms used by GS are not open or documented so that metrics cannot be verified. Citation analysis and scholarly metrics will be dealt with in the next chapter.

\subsection{ResearchGate}

ResearchGate is more focused on social interaction between scholars and restricts membership to academic researchers. Each member has a public profile with a list of publications, a synopsis of new publications in the field of research, a page with research questions regarding the specific discipline, as well as a scholarly metrics index, the RG-Score. This RG Score constitutes a rather unique index based on a proprietary design and computation basis. It seems to include the geographically and culturally very biased Thomson Reuters Web of Knowledge (WoK) database, on the one hand, as well as the researcher's social engagement on the platform, on the other hand: "anything researchers contribute to the network becomes a factor in their RG Score" (Tausch n.d.: 2). The RG Score changes on the basis of the scholars' involvement in the platform, independently of his/her publications, and is, thus, not well suited as a research assessment criterion: "We simply suggest to the ResearchGate decision makers to dump it into the dustbin of scientific errors and useless concepts, for good and forever" (Tausch n.d.: 3).

Overall, researchers seem to have reservations towards ResearchGate and their 'annoying policies' (Noorden 2014: 127), a geneticist, for example, is cited as saying "I've met basically no academics in my field with a favorable view of ResearchGate" (Noorden 2014: 126).

\subsection{Academia.edu}

Academia.edu is another popular social networking site for academics; according to their website "23,166,542 academics have signed up to Academia.edu, adding 6,167,754 papers" (July 2015). The site combines the feature of a publication archive integrating different document types with social networking capabilities, such as profiles, news feeds, recommendations, and the ability to follow individuals and subject fields or topics. The makers of Academia.edu stress their commitment to the principles of open science and open access. 


\subsection{ORCID}

ORCID was conceived as an "open, non-profit, community-based effort to provide a registry of unique researcher identifiers and a transparent method of linking research activities and outputs to these identifiers" (ORCID website) to avoid misidentification and author ambiguity problems. By becoming a member and getting the ORCID ID code, each scholar can enter basic personal information and affiliation, as well as a list of publications. ORCID basically, represents a searchable database of researchers, and is recommended by the SPRU (2015) report to be the "preferred system of unique identifiers" for the UK research system.

\subsection{ResearcherID}

More or less the same functionality is offered by ResearcherID which is part of Thomson Reuters and integrates into their Web of Science database. It is a free tool by a commercial provider.

\section{Research Evaluation}

Open Access and new academic publishing and communication platforms lead to more openness with regard to potential readership, and more transparency in publishing. The OA citation effect gives researchers a clear advantage as to when, and how often their publications are read and cited by fellow scholars. While this may translate into a better reputation and a higher selfesteem it is by no means a matter of course that it has the same positive impact on assessment procedures for careers and tenures. Here, we need to discuss the degree of openness and transparency of the different models of research evaluation which are of overall importance for researchers who still need to secure their career or livelihood.

Evaluation may be performed by direct or indirect research quality assessment (Rovira-Esteva and Orero 2012: 270), where a direct approach evaluates the works of an individual scholar or research group by looking at the quality, relevance, citation rate, or impact factor of his/her/their publications, and an indirect approach evaluates the works of an individual scholar or research group by looking at the scientific performance (quality/relevance/ citation rate/impact factor) of the journals, publishers, series where his/her/ their works were published. The first can be more intricate and difficult while the second, it is argued, saves time by relying on the assessment of an already done peer-review and quality assessment of journals or publishers.

1. In both cases a variety of quantitative and qualitative metrics are used to measure productivity outcomes and impact of scholars, journals 
and publishers, usually a combination of a quantitative analysis of publications - "authors, publication date, publication type, journal, publisher, etc., and statistical analyses in order to explain the growth (or decrease) of publication rates, the origin and evolution of disciplines, publication policy, interdisciplinarity, etc." (Grbić and Pöllabauer 2008: 5) -, a citation analyses by counting the citations of publications or journals to determine the impact on the discipline with the help of citation indexes and journal rankings, or a content analysis on publication data by measuring the occurrence and/or cooccurrence of certain keywords or subject classification categories in order to reveal trends regarding issues covered.

While counting publications seems to be sufficiently transparent, citation analysis is rather controversial. Basically, there are three ways in which citation analysis can be applied:

- to an individual article (how often it was cited);

- to an author (total citations, or average citation count per article);

- to a journal (average citation count for the articles in the journal), called the Journal Impact Factor (JIF).

To assess the impact, various calculations are done on the citation numbers and expressed in so-called impact factors. The most common is the h-index which "is a measure to quantify the cumulative impact of the publications of a scholar or research community by looking at the number of times those works have been cited" (Grbić and Pöllabauer 2008), a research community (or scholar) with an index of ' $\mathrm{H}$ ' has published ' $\mathrm{H}$ ' papers, each of which has been cited at least ' $\mathrm{H}$ ' times: "the higher the h-index, the more influential is the research community" (Xiangdong 2015: 185). Variations of the h-index such as the contemporary h-index or the individual h-index try to accommodate different parameters such as the number of authors per publications into the calculus. The g-index complements the $\mathrm{h}$-index by calculating the average citation rate of all publications of an author, also taking into account full citation numbers of very highly cited papers. A well documented tool which calculates H, G, and other indexes by using Google Scholar results is Harzing's Publish or Perish software (Harzing 2007).

While these data certainly provide an insight into the research impact of individual authors they should always be interpreted cautiously: different disciplines have divergent citation patterns or publication practices, such as the preference for book publications in humanities. Moreover, a citation may not always mean approval or recognition: the reason for citing a specific work could also be refusal or rejection, and the collection of citations may not be exhaustive as bibliographic databases tend to be work in progress. 
The most used databases for citation analysis are two commercial applications, the Web of Science by Thomson Reuters with their Arts and Humanities Citation Index $\mathrm{AHCl}$ and the Scopus database by Elseviers, and the freely accessible Google Scholar database. While the completeness and coverage of publications of the Web of Science has been criticized heavily since it "may provide a substantial underestimation of an individual academic's actual citation impact" (Harzing and van der Wal 2008: 62), the problems of applying the two commercial indexes to the humanities in general - "the Social sciences, Arts and Humanities, and engineering in particular seem to benefit from Google Scholar's better coverage of (citations in) books, conference proceedings and a wider range of journals" (Harzings PoP website) - and TS in particular, have been emphasized repeatedly. Franco Aixelá and RoviraEsteva (2015: 269) make clear that Google Scholar and Bitra, a specialized bibliographic database, are far more efficient in providing citations for articles in the subject field of TS than WoS/AHCl or Scopus; the latter do not treat TS as an autonomous discipline: "bibliometric tools such as BITRA or Google Scholar are beginning to provide a clearer picture of the impact of research in TS" (Franco Aixelá and Rovira-Esteva 2015: 277);

"Google Scholar results, even if it's not an index and data is mechanically gathered, throw a more objective and thorough results than the established and more valued indexes - with the added value of being free of access" (RoviraEsteva and Orero 2012: 271).

Openness as free access also means the reproducibility of assessments, and, thus, more transparency:

"Google Scholar provides an avenue for more transparency in tenure reviews, funding and other science policy issues, as it allows citation counts, and analyses based thereon, to be performed and duplicated by anyone" (Harzing 2008).

But free access alone is not enough for complete openness, the underlying data and algorithms have to be open and verifiable as well (SPRU 2015: 6): this seems not to be the case with the Web of Science, Scopus, and even Google Scholar. Still, citation analysis of articles and individual scholars constitute a transparent and verifiable method of assessment: "article-level citation metrics, for instance, might be useful indicators of academic impact, as long as they are interpreted in the light of disciplinary norms and with due regard to their limitations" (SPRU 2015 recommendation $\mathrm{n}^{\circ} 4$ ). Indirect assessment, in contrast, rates research work on the basis of where it has been published, using ratings or classifications of journals and publishers, thus, judging "our science by its wrapping rather than by its contents" (Seglen 1997: 501). 
Indirect assessment should, therefore, generally be rejected: "Journal-level metrics, such as the JIF, should not be used" (SPRU 2015 recommendation 4), and "do not use journal-based metrics, such as Journal Impact Factors, as a surrogate measure of the quality of individual research articles, to assess an individual scientist's contributions, or in hiring, promotion, or funding decisions" (San Francisco Declaration on Research Assessment DORA, recommendation 1). The reasons for this rejection were appropriately summarized by Seglen (1997: 498):

- The JIF "conceals the difference in article citation rates (articles in the most cited half of articles in a journal are cited 10 times as often as the least cited half)

- Journals' impact factors are determined by technicalities unrelated to the scientific quality of their articles

- Journals' impact factors depend on the research field: high impact factors are likely in journals covering large areas of basic research with a rapidly expanding but short lived literature that use many references per article

- Article citation rates determine the journal impact factor, not vice versa" (Seglen 1997: 498)

These arguments are shared by other scholars as well: Antelman (2004), for example, states with regard to the difference in article citation rates that "the high standard deviations of these samples bear this out and point to the value of new citation measures [...] Open-access articles make these new, more meaningful measures of research impact possible" (Antelman 2004: 380). The JIF should be restricted to the evaluation of journals and, in no case be extended to the assessment of an individual's work since

"the quality, reputation and impact of journals are therefore not achievements of the journals and their publishers: they are overwhelmingly achieved by the academic community that furnishes top-quality materials to them. After all, it's not journals that are cited but articles" (Blommaert 2014: 2).

Leaving aside arguments of a more general nature, indirect assessment through the JIF or other citation indexes is even more questionable when the humanities or, more specifically, TS are concerned. The common indexes are not suited for the humanities "because of their unsatisfactory coverage of European humanities research" (Franco Aixelá and Rovira-Esteva 2015: 268), proven by practical verification: "of more than 100 TS journals throughout the world (including both English and non-English TS journals), only 13 are indexed in the $\mathrm{SSCl}$ (Social Sciences Citation Index) or $\mathrm{AHCl}$ (Arts \& Humanities Citation Index) databases" (Xiangdong 2015: 184). This leads to a rather weak ranking of publications in TS. Even those listed are treated rather poorly in comparison to larger disciplines: "Impact Factors [...] of TS journals 
are low compared with other Linguistics journals" (Xiangdong 2015: 184), with negative effects for researchers: "this means TS scholars would be put in a disadvantaged position when being assessed against the same research assessment policy to decide their assignment, research ranking, promotion, and research funding, compared with Linguistics scholars" (Xiangdong 2015: 184).

To sum up, openness in assessment can only be achieved if individual scholars and research groups are evaluated directly, without recurring to journal impact factors. On the way "to a more open, accountable and outwardfacing research system" (SPRU 2015: 5), impact factors and numbers in general should better be avoided and supplanted by the term 'indicators' when the work of individual scholars is evaluated (SPRU 2015 recommendations). The Independent Review of the Role of Metrics in Research Assessment and Management (SPRU 2015) defines "responsible metrics" according to five parameters:

"Robustness: basing metrics on the best possible data in terms of accuracy and scope; Humility: recognising that quantitative evaluation should support - but not supplant - qualitative, expert assessment; Transparency: keeping data collection and analytical processes open and transparent, so that those being evaluated can test and verify the results; Diversity: accounting for variation by field, and using a variety of indicators to support diversity across the research system;

Reflexivity: recognising systemic and potential effects of indicators and updating them in response" (SPRU 2015: 7).

Implementing the guidelines and applying these principles in practice would guarantee more openness in evaluation procedures and research assessment.

\section{Conclusions}

The more scholars accept and adopt openness in their work, the more collaboration between researchers will take place, the faster research work will be read and processed, and the fairer assessment procedures will be. In summary, the advantages of open scholarship may be outlined schematically in the following diagram where the three areas of literature search, open publishing, and research assessment each generate specific advantages amplified through interaction with each other: 


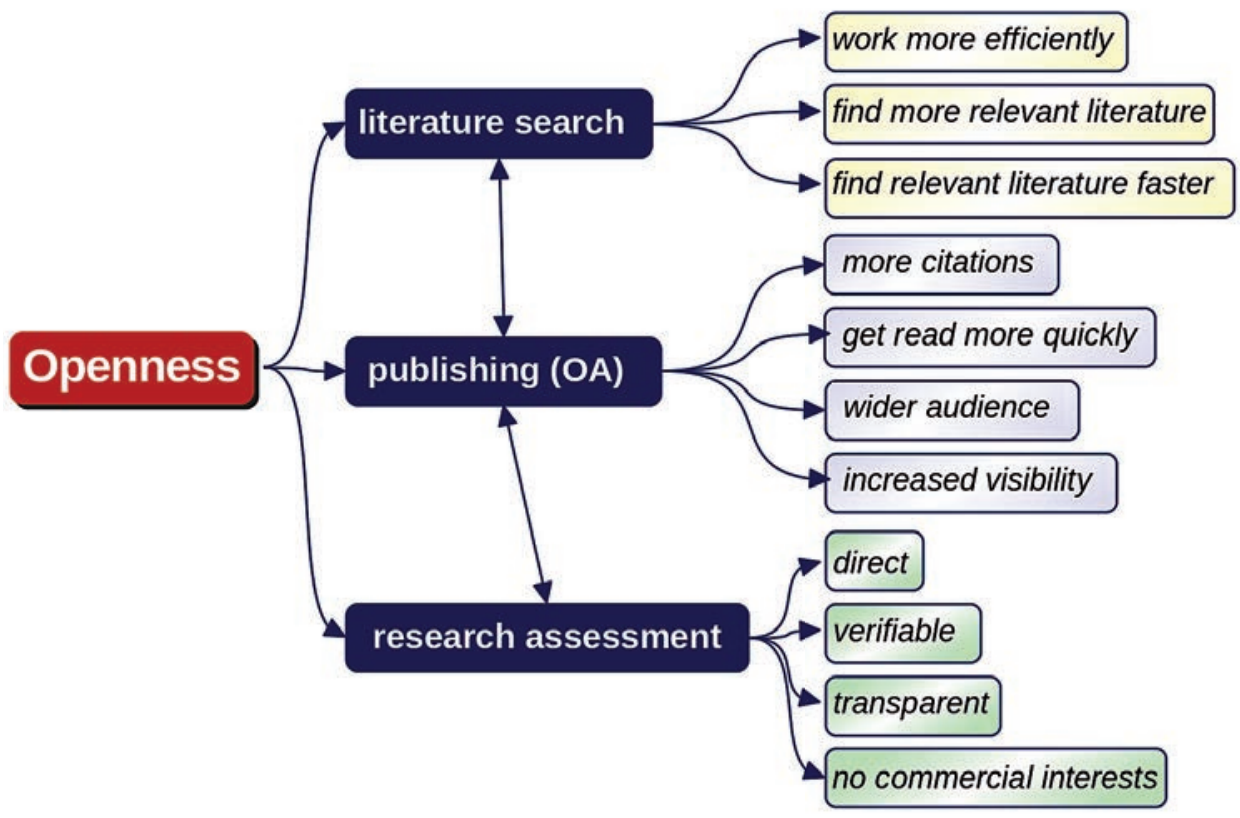

Figure 1: Advantages of openness.

A discipline can only gain from such an accelerated pace and transparent procedures, and, more importantly, isolated approaches and closed branches of theory will be avoided. This is especially important for TS where openness can help overcome ignorance and disregard of important literature as well as fragmentation of the discipline into mutually ignored schools of thought.

\section{References}

Antelman, K. (2004) Do Open-Access Articles Have a Greater Research Impact? Coll. res. libr. 9/65, 372-382; doi:10.5860/crl.65.5.372. Available at: http://crl.acrl.org/content/65/ 5/372.full.pdf+html [Accessed 3 August 2015].

AQU Workshop (2010) Research Assessment in the Humanities and Social Sciences. Eleventh Workshop - AQU Catalunya with the Catalan Universities, University of Barcelona, 28-29 January 2010. Available at http://www.aqu.cat/doc/ doc_86235770_1.pdf [Accessed 3 August 2015].

Blommaert, J. (2014) The Power of Free: In search of democratic academic publishing strategies. Tilburg Papers in Cultural Studies. Tilburg: Tilburg University. Paper 114. 
Davis, P. M., Lewenstein, B.V., Simon, D.H., Booth, J.G. and Connolly, M.J. (2008) Open access publishing, article downloads, and citations: randomised controlled trial. BMJ. BMJ Publishing Group Ltd. 337. Available at: http://www.bmj.com/content/337/bmj.a568 [Accessed 3 August 2015].

Davis, P. M. (2011) Open access, readership, citations: a randomized controlled trial of scientific journal publishing. The FASEB Journal. 25(7), 2129-2134. Available at: http://www.fasebj.org/content/25/7/2129.full.pdf [Accessed 2 August 2015].

Doty, R. C. (2013) Tenure-Track Science Faculty and the 'Open Access Citation Effect'. Journal of Librarianship and Scholarly Communication 1(3):eP1052. Available at: http://dx.doi.org/10.7710/2162-3309.1052 [Accessed 2 August 2015].

European Science Foundation ESF, Humanities unit (2009) Increasing visibility for a multifaceted humanities research in Europe - the ERIH approach. Available at: http://docslide.net/documents/erihpresentation2009.html [Accessed 3 August 2015].

Eysenbach, G. (2006) Citation Advantage of Open Access Articles, PLoS Biology 4(5): e157. Available at: http://journals.plos.org/plosbiology/article?id=10.1371/ journal.pbio.0040157 [Accessed 26 June 2015].

Fell, C. (2010) Publish or Perish und Google Scholar - ein Segen? Leibniz-Zentrum für Psychologische Information und Dokumentation (ZPID), Trier. Available at: http://www.zpid.de/pub/research/2010_Fell_Publish-or-Perish.pdf [Accessed 4 August 2015].

Franco Aixelá, J. and Rovira-Esteva, S. (2015) Publishing and impact criteria, and their bearing on Translation Studies: In search of comparability. Perspectives: Studies in Translatology, Special Issue: Bibliometric and Bibliographical Research in Translation Studies, 23(2), 265-283.

Gentzler, E. (2014) Translation Studies: Pre-Discipline, Discipline, Interdiscipline, and PostDiscipline. International Journal of Society, Culture \& Language, 2(2), 13-24. Available at: http://ijscl.net/pdf_5620_fdde5469d71359e7bb41dcee95329e13.html [Accessed 2 August 2015].

Gile, D. (2015) Analyzing Translation studies with scientometric data: from CIRIN to citation analysis. Perspectives: Studies in Translatology, Special Issue: Bibliometric and Bibliographical Research in Translation Studies, 23(2), 240-248.

Grbić, N. and Pöllabauer, S. (2008) To count or not to count: Scientometrics as a methodological tool for investigating research on translation and interpreting. Translation and Interpreting Studies 3. Amsterdam: John Benjamins Publishing, 87-146.

Hadley, J. (2014) List of Journals Publishing Translation Studies Research. Available at: https://www.academia.edu/11919672/List_of_Journals_Publishing_Translation_Studies _Research [Accessed 2 August 2015].

Harnad, S. and Brody T. (2004) Comparing the impact of open access (OA) vs. non-OA articles in the same journals. D-Lib Magazine 10(6). Available at:

http://eprints.soton.ac.uk/ 260207/1/06harnad.html [Accessed 2 August 2015].

Harzing, A. W. (2007) Publish or Perish. Available at: http://www.harzing.com/pop.htm [Accessed 2 August 2015].

Harzing, A. W. (2008) Google Scholar - a new data source for citation analysis. Available at: http://www.harzing.com/pop_gs.htm [Accessed 2 August 2015]. 
Harzing, A. W. and van der Wal, R. (2008) Google Scholar: the democratization of citation analysis? Ethics in Science and Environmental Politics, Vol 8, 61-73. Available at: http://www.int-res.com/articles/esep2008/8/e008p061.pdf [Accessed 3 August 2015].

Lawrence S. (2001) Free online availability substantially increases a paper's impact. Nature 411, 521. Available at: http://www.nature.com/nature/journal/v411/n6837/full/ 411521a0.html [Accessed 3 August 2015].

McCabe, M. J. and Snyder, C. M. (2013) Does Online Availability Increase Citations? Theory and Evidence from a Panel of Economics and Business Journals (March 14, 2013). Available at: http://ssrn.com/abstract=1746243 [Accessed 3 August 2015].

Noorden, R. van (2014) Scientists and the Social Network. Nature, vol. 512, 126-129. Available at: http://www.nature.com/polopoly_fs/1.15711!/menu/main/topColumns/ topLeftColumn/ pdf/512126a.pdf [Accessed 28 July 2015].

Norris, M., Oppenheim, C. and Rowland, F. (2008) The citation advantage of open-access articles. Journal of the American Society for Information Science and Technology. Wiley Subscription Services, Inc., A Wiley Company. 59, 1963-1972. Available at: http://onlinelibrary.wiley.com/doi/10.1002/asi.20898/abstract;jsessionid=A4CBF131B90 59A8E8748907EC9C883C0.f04t02 [accessed 3 August 2015].

Olsbo, P. (2013) Does openness and open access policy relate to the success of universities? Information Services and Use, 33 (2), 87-91. doi:10.3233/ISU-130707 Available at: http://elpub.scix.net/cgi-bin/works/Show?_id=110_elpub2013 [Accessed 3 August 2015].

RETI (n.d.) Journals of Translation and Interpreting Studies. University Library of Barcelona. Available at: http://www.bib.uab.cat/human/acreditacions/planes/publiques/ revistes/ revistescercaetieng.php [Accessed 3 August 2015].

Rovira-Esteva, S. and Orero, P. (2012) Evaluating quality and excellence in translation studies research: Publish or perish, the Spanish way. Babel 58(3), 264-288.

Rovira-Esteva, S., Orero, P. and Franco Aixelá, J. (2015) Bibliometric and bibliographical research in Translation Studies, Perspectives: Studies in Translatology, Special Issue: Bibliometric and Bibliographical Research in Translation Studies, 23(2), 159-160.

Seglen, P. O. (1997) Why the Impact Factor of Journals Should Not Be Used for Evaluating Research. British Medical Journal 314 (Feb. 1997), 498-502. Available at: http://www.ncbi.nlm.nih.gov/pmc/articles/PMC2126010/pdf/9056804.pdf [Accessed 3 August 2015].

Smith Rumsey, A. (2013) New-Model Scholarly Communication: Road Map for Change. Scholarly Communication Institute Reports 9, 2004-2011. University of Virginia Library, 157-188. Available at: http://www.uvasci.org/institutes-2003-2011/SCl-9-Road-Map-forChange.pdf [Accessed 3 August 2015].

SPRU - Science Policy Research Unit (2015) The Metric Tide: Report of the Independent Review of the Role of Metrics in Research Assessment and Management. Executive Summary. Available at: http://www.hefce.ac.uk/media/HEFCE,2014/Content/Pubs/ Independentresearch/2015/The,Metric,Tide/2015_metric_tide_executive_summary_an d_recommendations.pdf [Accessed 3 August 2015]].

Tausch, A. (n.d.) Researchgate, RG-Scores, or a true Research Gate to Global Research? On the limits of the RG factor and some scientometric evidence on how thecurrent RG score system discriminates against economic and social sciences and against the 
developing countries. Available at: https://www.academia.edu/2460163/ Researchgate RG-Scores_or_a_true_Research_Gate_to_Global_Research_On_the_limits_of_the RG_factor_and_some_scientometric_evidēence_on_how_the_current_RG_score m_discriminates_even_against_Nobel_Laureates_in_economics_and_against_the_dev elōping_countries [Accessed 3 Āugust 2015].

White, E. (2015) On Success and Working Openly in Science. OpenCon Community Webcasts. Available at: http://figshare.com/articles/On_success_and_working_openly_ in_ science/ 1476243 [Accessed 3 August 2015].

Willinsky, J. (2006) Access Principle: The Case for Open Access to Research and Scholarship. Cambridge: MIT press. Available at: http://mitpress.mit.edu/sites/default/ files/titles/content/9780262512664_Download_the_full_text.pdf [Accessed 3 August 2015].

Willinsky, J. (2010) Open access and academic reputation. Annals of Library and Information Studies. Cambridge: MIT Press. 57, 296-302.

Xiangdong, L. (2015) International visibility of mainland China Translation Studies community: A scientometric study. Perspectives: Studies in Translatology, Special Issue: Bibliometric and Bibliographical Research in Translation Studies, 23(2), 183-204. 